revista ANTHROPOLÓGICAS

Ano 24, 31(1): 196-219, 2020

\title{
Povos Tradicionais e a Questão Nuclear: conflitos socioambientais e resistências à central nuclear em Itacuruba
}

Whodson Silva ${ }^{a}$ Vânia Fialho ${ }^{b}$

O presente trabalho busca problematizar o campo sociopolítico em que se dá a instalação da Central Nuclear do Nordeste em Itacuruba, Sertão de Pernambuco - Brasil. Nossa análise considera o lugar que os povos tradicionais ocupam nessa arena de conflitos socioambientais. O cenário atual aponta para a consolidação de uma política nuclear que prioriza fatores como a importância militar da tecnologia nuclear e a sofisticação embutida nessa tecnologia que a apresenta como a forma de energia do futuro. Diante desse contexto, os povos tradicionais em Itacuruba têm elencado uma série de enfrentamentos no intuito de assegurar a proteção de suas territorialidades específicas frente à instalação do complexo nuclear no Rio São Francisco. Tais enfrentamentos configuram um repertório de ações coletivas e confrontos políticos na região do Sertão pernambucano.

Povos e comunidades tradicionais, Central Nuclear do Nordeste, Mobilizações antinucleares.

\section{Mudar para melhor? ${ }^{1}$}

As reflexões acerca do confronto de povos tradicionais com empreendimentos nucleares se inserem em uma agenda de pesquisas na

a Universidade Federal de Minas Gerais (UFMG), Projeto Nova Cartografia Social. Email: whodsoon@gmail.com.

b Universidade de Pernambuco (UPE), Projeto Nova Cartografia Social. Email: vania.antropologia@gmail.com. 
região do Sertão de Itaparica² ${ }^{2}$ do Laboratório de estudos sobre Ação Coletiva e Cultura da Universidade de Pernambuco (LACC-UPE). Este compreende o núcleo Pernambuco do Projeto Nova Cartografia Social (PNCS), atuante no Estado ${ }^{3}$ desde 2006 com foco nas auto cartografias de povos e comunidades tradicionais.

O confronto político, aqui problematizado, refere-se ao desbravado por uma série de agentes sociais no município de Itacuruba, entre os quais estão três grupos que se reconhecem como quilombolas: Negros de Gilu, Ingazeira e Poço dos Cavalos; e outros três que se reconhecem como indígenas: Pankará no Serrote dos Campos, Tuxá Campos e Tuxá Pajeú. Isto é, seis diferentes organizações sociais e políticas, bem como seis diferentes processos criativos de afirmação étnica e reelaborações culturais nessa região do Sertão.

Neste trabalho, a noção antropológica de 'povos e comunidades tradicionais' possibilita-nos compreender como tais coletivos, organizados em movimentos sociais, acionam identidades sociopolíticas que extrapolam a categoria analítica de comunidade camponesa:

\begin{abstract}
"Assim, uma unidade social que era classificada como 'comunidade camponesa', é vivida agora por seus integrantes e pode ser interpretada como 'comunidade remanescente de quilombo', como 'comunidade indígena', ou seja, como 'comunidade tradicional', incorporando atributos identitários e autodefinições, bem como formas distintas de reconhecimento pelo Estado e de redistribuições, sendo vista pelos seus próprios membros como uma unidade social peculiar, constituída por um processo histórico e uma 'tradição' inventada $^{4}$, e não apenas e tão somente como uma 'comunidade camponesa', analiticamente definida” (Almeida 2017:42).
\end{abstract}

Os povos tradicionais em Itacuruba reúnem um conjunto de demandas que os têm mobilizado para acessar direitos sociais específicos, discriminados na Constituição Federal de 1988 e em instrumentos jurídicos internacionais, como a Convenção 169 da Organização Internacional do Trabalho (OIT), sancionada no Brasil em 2002. Tais mobilizações denunciam que esses direitos são violentamente negados num sistemático contexto de 'descaso planejado', provocado pelo próprio Estado. 
A 'nova' Itacuruba constitui um município reconstruído pela Companhia Hidrelétrica do São Francisco (CHESF) para o reassentamento compulsório da população da 'velha' cidade, que fora inundada em 1988 em razão da instalação da Usina Hidrelétrica de Itaparica. O descaso planejado, como conceituou Parry Scott (2009), revela que os insucessos das medidas mitigadoras e as diversificadas formas de assédio à população impactada, já estavam presentes nas instruções e procedimentos administrativos da Usina Hidrelétrica (UHE) de Itaparica.

'Mudar para melhor!', esse era o slogan da campanha realizada pela CHESF para convencer a população dos benefícios da instalação do empreendimento. Os reais efeitos para estes, serão visualizados nos dados do Conselho Regional de Medicina de Pernambuco (CREMEPE) que, em 2006, apontava Itacuruba como a cidade brasileira com o maior índice de suicídios no Brasil, detendo 63\% de sua população com problemas de sofrimento mental ${ }^{5}$.

A atualidade do descaso planejado em Itacuruba é hoje veiculada em noticiários e em diferentes discursos políticos, que repercutem sobre a intenção do governo federal, por meio do Ministério de Minas e Energia (MME), de construir a Central Nuclear do Nordeste, às margens do Rio São Francisco, sendo Itacuruba o sítio pleiteado para projeção de até seis reatores nucleares, com capacidade total de 6.600 megawatts elétricos e um investimento de R\$ 64,404 bilhões ${ }^{6}$.

A partir de 2011, de estigmatizada 'terra dos deprimidos'7, nova Itacuruba passa à potência nuclear brasileira. No entanto, se de um lado o setor do desenvolvimento energético no Brasil caminha para a materialização do empreendimento nuclear em Itacuruba, de outro, se atiçam as mobilizações antinucleares nessa região, sendo sobre estas a nossa argumentação.

Versaremos, portanto, sobre os mecanismos de enfrentamento de indígenas e quilombolas em Itacuruba no confronto com a central nuclear. Esta arena de interações e conflitos, dos mais diversos, situará os sujeitos em posições diferentes de domínio, em ambientes ancorados e atravessados por desigualdades de poder. 
Nossa compreensão do confronto antinuclear, segue na direção de McAdam, Tarrow \& Tilly (2009), em que um 'confronto político' envolve uma interação coletiva, na medida em que: (a) ela envolve confronto, é dizer, faz reivindicações vinculadas a outros interesses e (b) pelo menos um grupo da interação, incluindo terceiros, é um governo, isto é, uma organização que controla os principais meios de coerção concentrados num território definido.

No tocante à primeira questão, 'os outros interesses' referem-se aos que elencamos como discussão analítica e que se configuram, no contexto de enfrentamentos, como interesses contrários aos do empreendimento, não no sentido redutivo de que os povos tradicionais 'não querem desenvolvimento' ou são empecilhos para tal, mas entendem que o desenvolvimento, tal qual está posto, não atende às suas necessidades. De forma arbitrária, o desenvolvimento impacta o meio ambiente em que vivem, impulsiona o medo e a insegurança; tudo estrategicamente invisibilizado pelos planejadores.

A segunda questão atenta para o papel do Estado, já que este, no contexto do confronto, controla os principais meios de coerção, o que restringe o campo de possibilidades das ações coletivas de agentes opositores. Nosso argumento é de que o Estado ocupa um lugar de 'consórcio' na arena de ações e negociações da Central Nuclear do Nordeste, que segundo Ribeiro refere-se a:

"um processo político comandado por grupos de poder que operam em níveis mais elevados de integração. É um encadeamento que mediante a organização de novas entidades orientadas a tarefas econômicas e administrativas - une, de fato, dentro de um projeto, instituiç̃es e capitais internacionais, nacionais e regionais. É uma forma de reforçar relacionamentos capitalistas de modo piramidal, em que níveis mais elevados hegemonizam níveis mais baixos. $\mathrm{O}$ consórcio é a entidade social, econômica, e política concreta que articula diferentes grupos de poder" (Ribeiro 2008:115).

Entender a atuação do Estado como um consórcio na trama sociopolítica e econômica que conjectura a instalação da central nuclear possibilita-nos indagar o porquê de tal projeto e a quem este interessa 
e beneficia. Seguramente não aos povos tradicionais, que em resposta, elencam uma série de reivindicações apoiadas em marcos legais que impõem a necessidade de consulta livre, prévia e informada sobre os interesses dos seis grupos, sem exceção, nas áreas a serem ocupadas ou atingidas pela Central Nuclear do Nordeste, sendo este um procedimento condicionante para a construção do empreendimento.

$\mathrm{Na}$ direção de complexificarmos o campo social assinalado, situaremos a questão nuclear em Itacuruba e destacaremos o 'repertório confrontacional' que tem sido estabelecido pelos povos tradicionais nessa região. Tal conjuntura aponta o acirramento de políticas governamentais que impulsionam a implantação de grandes projetos e objetivam, ao mesmo tempo, retroceder os direitos conquistados pelos segmentos sociais, assim como impactar o meio ambiente em escalas sem precedentes.

\section{Itacuruba 'no meio' da rota de expansão da energia nuclear brasileira}

Num panorama histórico, a discussão sobre a possibilidade do Sertão de Itaparica abrigar um empreendimento nuclear surge ainda na década de 1980, período em que o Estado anuncia o alcance da tecnologia para o enriquecimento do urânio, bem como promovia o reassentamento compulsório da população de Itacuruba.

O Diário Oficial da Prefeitura da Cidade do Recife, de 17 e 18 de junho de 1987, registra uma campanha que se desencadeava com o apoio da mesma prefeitura e tinha por finalidade "coletar 30 mil assinaturas para viabilizar emenda constitucional de caráter popular, contra a instalação de uma usina nuclear em Pernambuco". Em 25 de novembro do mesmo ano, a 'Emenda Substitutiva $n^{\circ} 01$ ao Projeto ${ }^{\circ}$ 244' é discutida pelos deputados estaduais e registrada no Diário do Poder legislativo de Pernambuco. A emenda propunha proibir "aos governos do Estado e dos Municípios celebrarem convênios ou darem licenças que possibilitem a instalação de usinas nucleares, ou que permitam o depósito de seus rejeitos ou de química letal". Salienta-se que 
o governo federal também pretendia depositar no município de Floresta, vizinho à Itacuruba, o lixo atômico da tragédia envolvendo o Césio - 137 que ocorreu nesse mesmo ano em Goiânia (GO) (Diário Oficial do Estado de Pernambuco - Poder Legislativo, 25.11.1987, p. 04).

Da década de 1980 até o momento, tais discussões dinamizaramse e, mais recente, acompanhamos uma locomotiva de expansão da produção nuclear no Brasil, estando Itacuruba 'no meio' da rota dessa locomotiva. Como noticiado pelo Blog de Jamildo, do Sistema Jornal do Commercio, que em 11 de fevereiro de 2011 veiculou a matéria: 'Eletronuclear escolhe cidade de Itacuruba como opção para uma usina atômica no Nordeste' ${ }^{8}$. A matéria traria em anexo o projeto 'A rota de expansão da energia nuclear brasileira', assinado em Janeiro de 2011 pelo engenheiro Carlos Henrique Mariz, à época, chefe do escritório da Eletronuclear ${ }^{9}$ no Nordeste. $\mathrm{O}$ documento justifica Itacuruba como primeira opção para sediar o empreendimento, por apresentar "baixa densidade populacional, oferta de água para resfriar os reatores, solo estável e proximidade das linhas de transmissão de energia”.

É a partir desse momento, e nessas condições, que se torna pública a informação de que Itacuruba reviveria os dramas sociais de uma relação histórica com o setor do desenvolvimento energético. A Central Nuclear do Nordeste é projetada ao longo dos anos 2000 quando, ainda em 2006, se retoma a discussão do Plano Nuclear Brasileiro (PNB). Nesse período, confluiu na região Nordeste uma série de obras de investimentos do Programa de Aceleração de Crescimento (PAC). Concomitante aos investimentos no Nordeste, a população de Angra dos Reis, no Rio de Janeiro, veria novamente o desempenho do PNB, no retorno as obras de Angra 3, que paradas desde 1986, entrara na lista de prioridades do PAC.

Em 12 de agosto de 2009 inaugura-se o escritório da Eletronuclear na cidade de Recife. $\mathrm{O}$ site do $\mathrm{MME}^{10}$ afirmava que a representação de tal empresa no Nordeste se dava em "função de atender à demanda que será criada a partir do início dos estudos para escolha do sítio da central nuclear nordestina como, por exemplo, o envolvimento com 
as organizações públicas e regulatórias da região”. A área considerada "de interesse", segundo notícia, "é a faixa litorânea que vai da Bahia a Pernambuco passando por Alagoas e Sergipe".

\section{A QUESTÃO NUCLEAR EM ITACURUBA}

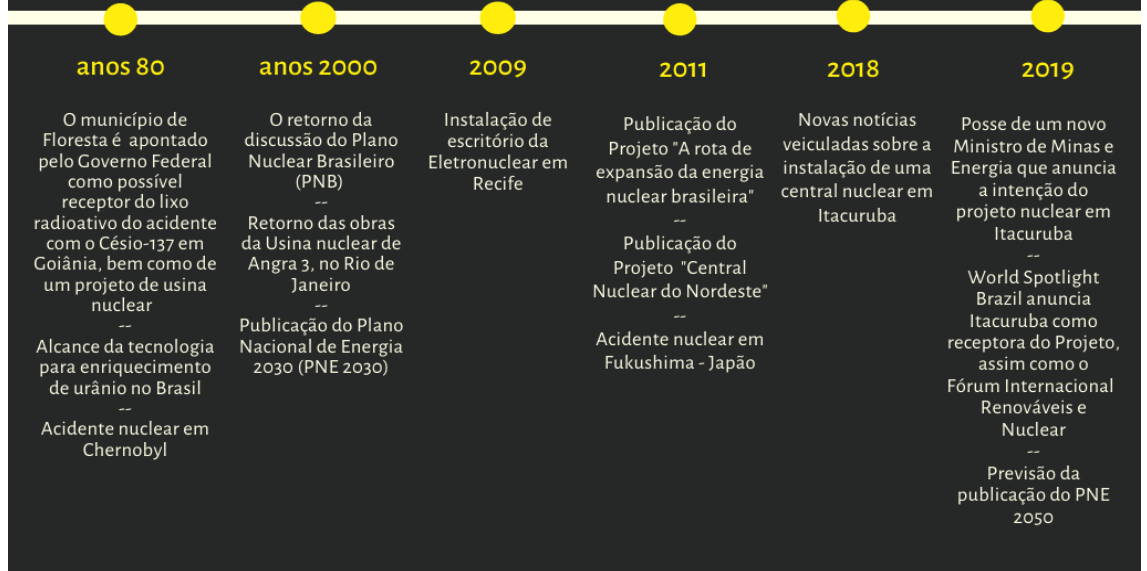

Figura 01. A questão nuclear em Itacuruba. Fonte: Silva (2019).

"É o município de Itacuruba, à beira do Rio São Francisco, perto de Belém de São Francisco, onde poderá vir a ser construída a nova central nuclear do país, com seis unidades geradoras e capacidade total de 6,9 mil MW" - afirma a nota da Associação Brasileira de Energia Nuclear $(\mathrm{ABEN})^{11}$, de agosto de 2013, período em que a Eletronuclear estava na fase final do estudo.

O projeto da 'Central Nuclear do Nordeste', disponível digitalmente no site da Eletronuclear até julho de $2018^{12}$, ratificou a escolha desse sítio, prevendo a construção de seis usinas nucleares, onde a 
primeira iniciaria a operação em 2022 e a última em 2030. Segundo o projeto, a construção de cada uma das usinas se daria em um prazo de 05 anos, inspirados no projeto da Sanmen Nuclear Power Station em Zhejiang, China ${ }^{13}$. Na categoria de impacto regional, são listados como municípios diretamente impactados: Belém do São Francisco (PE), Rodelas (BA), Itacuruba (PE), Floresta (PE), Cabrobó (PE), Salgueiro (PE), Serra Talhada (PE), Petrolândia (PE) e Paulo Afonso (BA).

Entre 2011 e 2017, há um silêncio deliberado do governo federal sobre a instalação desse projeto, um dos motivos para tal retaguarda do Estado deve-se ao fato de que, ainda em março de 2011, ocorre o desastre nuclear na Central de Fukushima - Japão. Tal evento acaba por repercutir num debate mundial sobre os riscos de empreendimentos nucleares para a humanidade, bem como nos argumentos dos movimentos antinucleares em Pernambuco, que despontaram nesse mesmo ano.

É a partir de 2018, no entanto, que se retoma o debate da questão nuclear em Itacuruba. O Comitê de Desenvolvimento do Programa Nuclear Brasileiro (CDPNB), organismo vinculado ao Palácio do Planalto, em julho de 2018, já tinha elaborado a proposta de um programa que previa ampliar a geração de energia nuclear no país, aumentar a exportação de urânio e dinamizar a mineração do setor. $\mathrm{O}$ comitê, que nesse momento estava composto por representantes de onze ministérios e coordenado pelo ministro do Gabinete de Segurança Institucional (GSI), teria criado sete grupos de trabalho sobre o tema nuclear para estruturar o novo PNB. As proposições eram de projetos de novas usinas nucleares em diferentes partes do país e o retorno das obras de Angra $3^{14}$.

Com a posse de um importante almirante de esquadra ao MME, o setor do desenvolvimento nuclear ganha mais expressão. Entre as pautas anunciadas pelo ministro, em março de 2019, está a transferência da exploração do urânio para a iniciativa privada ${ }^{15}$ que - pela Constituição Federal do país é de monopólio da União na figura da estatal Indústrias Nucleares do Brasil (INB) - e a abertura das reser- 
vas indígenas para a indústria de mineração ${ }^{16}$. Em janeiro de 2019 o MME já havia declarado, por meio de nota oficial, a pretensão de retomar as obras de Angra 3 e o plano de construir entre quatro e oito novas usinas nucleares no País:

"Para o setor nuclear, a conclusão de Angra 3 é importante, pois traz escala à toda a cadeia produtiva do setor, desde a produção de combustível à geração de energia. Isso se torna ainda mais relevante quando se leva em conta que o Brasil vai precisar investir em energia para o futuro, em função do aumento da demanda e do esgotamento do potencial hidrelétrico. Por fim, o Plano Nacional de Energia 2030 (PNE 2030) prevê a construção de quatro a oito usinas nucleares no País. Cenário que tende a ser confirmado pelo PNE 2050, publicação aguardada para breve" (Nota do Ministério de Minas e Energia em 22 de janeiro de 2019) ${ }^{17}$.

Mais recente, em abril de 2019, o MME anunciou, durante o World Spotlight Brazil no Rio de Janeiro, que uma área em Pernambuco já teria sido analisada pela Eletronuclear para receber uma nova central nuclear. $O$ local consistia num sítio, que fica localizado na cidade de Itacuruba e poderia abrigar até seis reatores nucleares, totalizando uma capacidade de 6.600 megawatts elétricos. A escolha de tal município foi ratificado no Fórum Internacional Renováveis e Nuclear, realizado em 04 de Julho de 2019, no Auditório da TV Jornal em Recife.

Atualmente, estão em operação as usinas nucleares de Angra 1, com capacidade para geração de 640 megawatts elétricos, e de Angra 2, com capacidade para 1350 megawatts elétricos. Estas duas usinas respondem pela geração de 3\% da energia elétrica consumida no Brasil. Angra 3, que foi projetada como praticamente uma réplica de Angra 2, prevê a geração de 1405 megawatts elétricos, caso venha a operar ${ }^{18}$. O PNE 2030, que subsidia o governo na formulação de sua estratégia para a expansão da oferta de energia até 2030, aponta a necessidade da construção de novas centrais nucleares nas regiões Nordeste e Sudeste, algo que tende a ser confirmado no PNE 2050, publicação aguardada para 2020. 
Este cenário aponta para a consolidação de uma política nuclear brasileira que considera fatores como a importância militar da tecnologia nuclear e a sua sofisticação, que se apresenta como a forma de 'energia do futuro'. Tais parâmetros explicam a formação de um setor nuclear no país e a preferência por esse tipo de fonte de energia, como afirma Pinguelli Rosa (1988).

É a partir do momento em que os planejadores traçam a rota da expansão da energia nuclear brasileira, estando Itacuruba bem 'no meio' dessa rota, que se difunde entre a população itacurubense toda uma relação de 'medo difuso', que ancorará até os dias atuais uma escancarada forma de 'violência do silêncio' praticada pelo Estado com essa população.

"Em Angra dos Reis, onde a experiência com a radioatividade não se manifesta sensorialmente, a proximidade da usina nuclear parece não provocar a mesma reação da população, ou não da mesma maneira. Ela se manifesta através de um medo difuso ${ }^{19}$ originário da circulação de informações sobre os riscos da radioatividade [...]". (Leite Lopes 2004:234).

Se a presença da central nuclear em Angra dos Reis incita um sentimento de medo nas pessoas que sensorialmente não identificam se estão sendo 'envenenadas' pela exposição à radiação, a população de Itacuruba, antes mesmo de estar exposta a esses riscos, passa a viver de forma ainda mais intensificada, a partir de 2011, severas dimensões do sofrimento social provocadas pelo medo da instalação de um novo empreendimento energético no município. A violência do silêncio, como destacamos em Silva (2019), é um desses prejuízos que o poder político, econômico e institucional engendra nessa região, sendo um perverso mecanismo de desmoralização dos agentes sociais impactados.

Primeiro, o Estado não oferece 'maiores informações' sobre as áreas de interesse do empreendimento nuclear, mesmo quando requerido pelos povos tradicionais que têm esse direito constitucionalmente garantido. Segundo, os técnicos e gestores entusiastas da energia 
nuclear negam a existência do projeto, apelando para viralização midiática de que o tema da central nuclear em Itacuruba é 'fake news' ${ }^{20}$, estigmatizando a população como 'louca', 'depressiva' e 'desinformada'; Terceiro, conforma-se um lobby nuclear que confirma Itacuruba como o local que 'poderá' receber tal investimento; a 'indecisão' do Estado justifica a ausência de informações e consulta às comunidades, tratando-as como ignorantes da discussão técnica, científica e econômica do empreendimento nuclear.

'Loucos', 'interesseiros' e 'ignorantes' têm sido alguns dos adjetivos utilizados pelos técnicos, planejadores e parlamentares para coibirem as ações de um movimento que se situa como contrário a investimentos nucleares em 'Itacuruba, no Nordeste e no Brasil!'. Trata-se da Articulação Sertão Antinuclear, a qual integram os povos tradicionais, que busca impedir a construção de centrais nucleares no Rio São Francisco e a reparação ética de todo um contexto de descaso planejado em que tais populações são atualizadamente submetidas.

\section{Repertórios confrontacionais de povos tradicionais em Itacuruba}

“Dizemos não à usina nuclear no São Francisco!" é a afirmação dos povos tradicionais em Itacuruba que, exponencialmente, vêm configurando uma série de mobilizações antinucleares no Sertão de Pernambuco. Tais mobilizações, antes de tudo, chamam-nos atenção por se apresentarem empiricamente como contraponto de todo um processo de produção de invisibilidade desses grupos no projeto da Central Nuclear do Nordeste.

É esse sertão visto sob a lente do vazio demográfico, da miséria e dos estigmas sociais que marcam visões desfiguradas que passam a ser registradas e tornadas como verdades num projeto que se apresenta como a tábua de salvação, única e perfeita! Entretanto, são as formas de resistência dos povos tradicionais ao empreendimento nuclear que visibilizam a presença histórica, material e simbólica de diversificadas coletividades em toda essa região. 


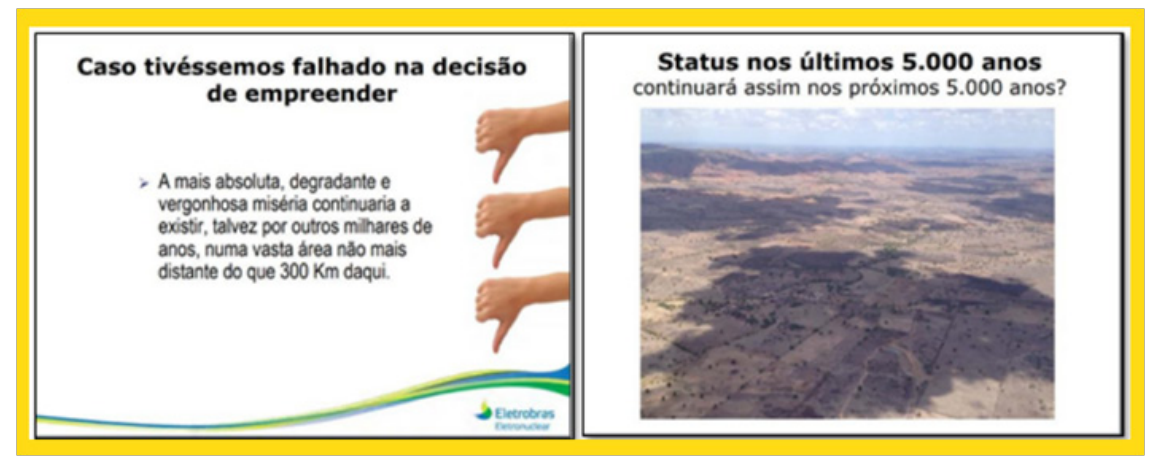

Figura 02. Folhas 65 e 66 do Projeto 'Central Nuclear do Nordeste’. Fonte: Eletrobrás/ Eletronuclear (2011).

"Existem indígenas, quilombolas, ribeirinhos, pescadores, toda população ali em torno de onde quer ser feito a usina nuclear!", coloca-nos Jorge Pankará ${ }^{21}$. "Nós da Aldeia Tuxá de Itacuruba somos vizinhos da provável usina nuclear, a gente fica lado a lado de onde ela vai ser construída", afirma Evani Tuxá. "Existimos!", "Estamos aqui!" e "não iremos sair!", são três afirmações que são persistentemente afirmadas pelos povos tradicionais e que se apresentam como prontas respostas aos adjetivos deturpados que vem desqualificando o lugar de fala e a fala destes.

Se, de fato, a usina for construída, provavelmente nós teremos de ser retirados do território ou ficaremos numa área de segurança máxima, qual das duas decisões a gente tem que tomar? O que vamos fazer? Para que caminho a gente vai seguir? Se não é nenhuma das que a gente quer, nenhuma das possibilidades a gente quer, então é esse o grande empasse que a gente tem ou nós ficamos dentro de uma área de segurança máxima ou a gente é retirado de um território que a gente vem lutando, o território tradicional, e aí mais uma vez nós vamos negar aos nossos filhos e aos nossos netos o território, a cultura, a tradição se nós já passamos por isso? Por isso que a gente continua denunciando! (Lucélia Pankará).

Muitas pessoas também me procuram pedindo sugestões em relação à questão da usina nuclear. Eu começo a colocar o concreto 
que a gente já tem em vida, o resultado da Barragem de Itaparica como já foi colocado aqui, e a questão também da transposição do São Francisco que a gente tem fatos concretos que foi exatamente assim, famílias induzidas às promessas, as benditas promessas que vem de cima. Cadê que metade delas são cumpridas? Quantos anos nós já temos da usina de Itaparica? E quantas pendências ficaram e que a gente nunca mais conseguiu solucionar? Cadê o resultado? Foi prometido e não foi cumprido! (Valdeci Ana, Quilombo Poço dos Cavalos).

Os Povos tradicionais em Itacuruba denunciam uma série de assédios provocados pela ação desenvolvimentista do Estado, que negligencia historicamente os direitos sociais de tais populações, propondo projetos que integram interesses de instituições e capitais internacionais, nacionais e regionais que acabam por desajustar os mais diversos contextos locais. Em uma conjuntura de dispersão e fragmentação, as existências e afirmações de grupos enquanto etnicamente diferentes evidenciam os mecanismos de resistência desses ao projeto da central nuclear. É "fortalecendo a cultura, a fé e a religião", como afirma Cícera Pankará. É na luta pela demarcação dos territórios e pela preservação do Rio São Francisco, onde se abundam as mais variadas formas de resistências que compõem, numa esfera maior, repertórios de confrontos antinucleares no Sertão de Pernambuco.

A ideia de 'repertório confrontacional', no uso de McAdam, Tarrow \& Tilly (2009), refere-se a um conjunto de formas de ação política surgida em meio a conflitos numa dada época e que, a partir de então, fica à disposição dos atores sociais (Alonso \& Botelho 2012). Lançando mão desse conceito, veremos que os povos tradicionais em Itacuruba conformam repertórios confrontacionais, onde mobilizados para obstar o empreendimento, elencam uma série de ações políticas que expressam uma interação histórica e atual entre eles e seus opositores, nesse caso, os projetos desenvolvimentistas do Estado.

As ações políticas que irão compor os repertórios confrontacionais podem ser vistas nas microdinâmicas locais, nos processos e nos ambientes próprios de cada grupo, ou seja, na realidade vivida no 
contexto de Itacuruba, onde é a própria 'vida' o eminente elemento de resistência e de confronto político. O que James Scott (2002) conceituou como 'formas cotidianas de resistências' é particularmente importante para demonstrar que o enfrentamento não se expressa somente em manifestos, protestos e batalhas mais rápidas, mas também num bojo de lutas pulverizadas no dia a dia de pessoas que, imersas em suas dinâmicas, encontram obstáculos para a ação coletiva e organizada, sendo as resistências cotidianas muitas vezes a única opção disponível. A reivindicação por escolas e por uma educação indígena específica e diferenciada; o empenho de lideranças quilombolas e indígenas em encaminhar os processos administrativos de regularização de seus territórios; e as articulações associativas locais são alguns dos exemplos das formas cotidianas de resistências.

Em uma mesma direção, mas em um plano paralelo, visualizaremos outro campo de ações políticas de povos tradicionais, esse especificamente se voltará para uma unidade de mobilização antinuclear que desponta em Pernambuco e revela um circuito de interações políticas em Itacuruba e fora desta. Segundo Almeida uma "unidade de mobilização" pode ser compreendida como:

"uma aglutinação de interesses específicos de grupos sociais não necessariamente homogêneos que são aproximados circunstancialmente pelo poder nivelador do Estado - por meio de políticas desenvolvimentistas, ambientais e agrárias - ou das ações por ele incentivadas ou empreendidas, tais como as chamadas obras de infraestrutura" (Almeida 2004:10).

A unidade de mobilização antinuclear que se opõe à construção da Central Nuclear do Nordeste nomina-se Articulação Sertão Antinuclear. Esta canaliza manifestações públicas que indicam ao restante da sociedade as problemáticas socioambientais e tecnológicas de um empreendimento dessa natureza. Registramos neste trabalho o confronto antinuclear de povos tradicionais a partir das atividades encabeçadas por essa Articulação, considerando que essas coletividades ocupam um importante lugar de ação e discurso na referida unidade 
de mobilização, isso porque a conformação desta só foi possível em decorrência das alianças e redes de solidariedade política, provocadas pela existência e demanda dos próprios povos tradicionais em Itacuruba.

Entendemos, assim, como os diferentes movimentos sociais, povos tradicionais de outros municípios, grupos de pesquisa das universidades, entre outras instituições, se aglutinam em uma unidade de confronto antinuclear. É o exemplo dos setores ligados à Igreja Católica, como a Diocese de Floresta, Conselho Indigenista Missionário (CIMI), Comissão Pastoral da Terra (CPT) e Comissão Pastoral de Pescadores (CPP), que entendem que a Igreja e a sociedade precisam atuar "em comunhão e a favor dos irmãos excluídos" 22 , salvaguardando seus direitos.

Analiticamente, compreendemos que os repertórios confrontacionais da Articulação Sertão Antinuclear são situacionais, isto é, ações políticas que são realizadas em determinado tempo e espaço, com determinados atores e em certas circunstâncias. Para McAdam, Tarrow \& Tilly (2009), o uso repetido do mesmo repertório diminui sua eficácia instrumental e, desta forma, encoraja a inovação tática, no entanto, os repertórios têm também uma função expressiva cuja lógica encoraja a persistência em vez da mudança. São essas as tensões criativas entre persistência e inovação de ações políticas que corporificam os repertórios da Articulação Sertão Antinuclear.

Dessa maneira, apreendemos a existência de dois desses repertórios: um que teve início em 2011, impulsionado pelas notícias veiculadas no Sistema Jornal do Commercio, dispersando-se em 2014 com o silenciamento das informações sobre o empreendimento nuclear; e o outro que tem início em 2019, com as novas notícias da intenção do projeto nuclear em Itacuruba e são simultâneas ao período em que escrevemos este trabalho. Poderíamos analisar o conjunto de ações políticas da Articulação Sertão Antinuclear a partir de um único recorte temporal, não obstante, problematizamos o atual cenário sociopolítico em que se dá a construção emergente do segundo repertório confrontacional: 
"O atual contexto que provocará o campo de oportunidades de novas ações coletivas de povos tradicionais contra o empreendimento nuclear apresenta-se como distinto justamente por: (a) explicitamente demonstrar a concretude da instalação de um complexo nuclear em Itacuruba, mesmo que a população não tenha sido notificada oficialmente e que, em detrimento disso, surjam informações de que tal notícia é 'fake News' para deslegitimar o movimento antinuclear que desponta atualmente no Sertão de Pernambuco; (b) evidenciar que a decisão política de construção de empreendimentos nucleares no Brasil assumidamente vai à contramão da discussão energética mundial, que, a sua vez, acentua formas de energia renovável e regressão das políticas nucleares; (c) limitar e inibir as formas de ação coletiva de segmentos sociais através de um contexto sociopolítico que criminaliza e negligencia os movimentos sociais, não escutando suas demandas mesmo que constitucionalmente lhes sejam assegurados; e, (d) o próprio contexto da conformação do movimento antinuclear desembocará em novas estratégias de ação que configurará um novo repertório confrontacional” (Silva 2019:139).

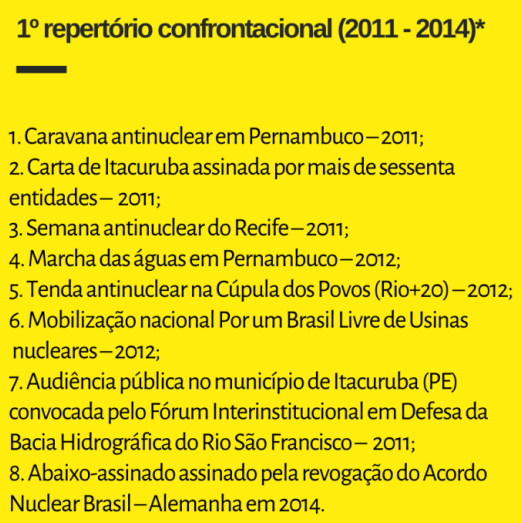

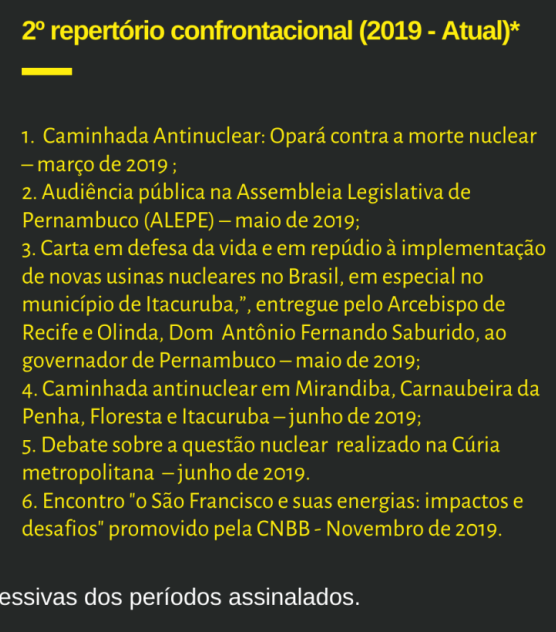

Figura 03. Quadro dos repertórios confrontacionais antinucleares em Pernambuco. Fonte: os autores.

Configura-se, desde 2011, um itinerário de mobilizações antinucleares em Pernambuco, expressos em repertórios confrontacionais, 
que fundam uma construção argumentativa para que o projeto da Central Nuclear do Nordeste não seja tratado a partir da ideia de uma tábula rasa. A Articulação Sertão Antinuclear, nessa perspectiva, vem expondo os motivos pelos quais um projeto dessa natureza não possibilitaria reais benefícios para tal região. Mais do que isso, se apresenta como um contraponto aos infundados argumentos de técnicos e planejadores sobre o 'vazio demográfico' e de uma imaginária 'prosperidade' e 'benesses' que abarcará as populações impactadas.

Tendo em vista os dados apresentados, nossa análise é de que a projeção de uma central nuclear no Nordeste não é um fato isolado e localizado, pelo contrário, envolve uma série de elementos, atores, instituições e conflitos que permeiam diferentes níveis e espaços de poder. E, nessa direção, é importante considerar que os aspectos sociais e ambientais que estão no entorno da instalação de um megaprojeto energético não devem ser tratados separadamente ou por último, pelo contrário, devem estar em pé de igualdade com os fatores técnicos e econômicos no próprio processo de planejamento.

\section{Considerações finais: a agenda de estudos confrontacionais}

A agenda de estudos confrontacionais consiste num trajeto de pesquisas que tem sido estabelecido na RD do Sertão de Itaparica, com o objetivo de problematizar os efeitos de um conjunto de políticas governamentais, voltadas para os setores da mineração e da energia, que são gerenciados por conglomerados econômicos e vêm impactando povos e comunidades tradicionais nesta região. Essas investigações salientam que os elementos e dados socioantropológicos e ambientais não devem ser negligenciados ou banalizados, como têm sido perversamente recebidos na arena de ações e negociações da central nuclear em Itacuruba.

É preciso ressaltar que o enfrentamento da discussão sobre matriz energética não é recente no campo da antropologia. Porém as mudanças e as possibilidades que a própria tecnologia nos traz como 
opção, acabaram por definir alguns preceitos para se refletir sobre o tema, assim como possibilitam algumas constatações.

A primeira delas é a desconsideração das questões apresentadas pela antropologia ao tema. Geralmente, como assinala Brooks (2012), somente depois das tragédias acontecidas é que e o saber antropológico é chamado a opinar e a explicar o evento desastroso. Considerar os estudos socioantropológicos quer dizer assumir que o problema de energia não é apenas tecnológico, mas social e cultural. Uma abordagem mais abrangente e contextual, como destacam Nader, Cesarino \& Hebdonuma (2010), precisa ir além de uma perspectiva técnica estreita para incluir política e poder, a fim de entender as raízes passadas e as ramificações atuais de nossos dilemas energéticos.

É diante do cenário que vimos tratando neste trabalho que podemos constatar que os confrontos políticos são emergentes e atuais mas, no entanto, visibilizam uma série de assédios provocados pela ação dos megaempreendimentos de infraestrutura, que incidem nessa região desde os anos de 1950 e se firmam na atual conjuntura política neoliberal. As denúncias, manifestações públicas, entre tantas diversificadas formas de ação coletiva emergentes nesse confronto, comunicam um atualizado processo de descaso planejado ao qual essas populações são historicamente submetidas e revelam, sobretudo, um contínuo enredo de violação de direitos de povos tradicionais roteirizado pelo Estado brasileiro.

Se de um lado os confrontos políticos comunicam tal bojo de violências, de outro se evidenciam os mecanismos de resistência que são criativamente reelaborados em contextos de conflitos socioambientais, o que demanda das ciências sociais e ambientais reflexões que deem conta de problematizar as desigualdades de poder que atravessam a arena de instalação de projetos ditos de 'interesse nacional', mas que acoplam um complexo lobby de interesses que não são da esfera nacional e pública.

Os confrontos políticos de povos tradicionais, nessa direção, têm possibilitado a produção de uma série de estudos que exploram como 
nos contextos locais se produzem estratégias para a sobrevivência, autonomia e acesso aos direitos sociais que são constitucionalmente assegurados. Tais investigações se contrapõem às interpretações de espaços cristalizados como vazios e decadentes e chamam atenção para as existências e resistências dos grupos sociais aos projetos desenvolvimentistas que os desconsideram como sujeitos de direito.

Referimo-nos às pesquisas de mestrado e doutorado de integrantes do núcleo Pernambuco do Projeto Nova Cartografia Social, que vêm discutindo e produzindo reflexões acuradas sobre os conflitos socioambientais presentes no Sertão de Itaparica, aqui em destaque a dissertação de mestrado de Silva (2019) sobre a expansão geopolítica da energia nuclear e o confronto antinuclear de povos tradicionais, a pesquisa doutoral de Poliana Nascimento sobre a exploração mineral e as dinâmicas do capital econômico nesse circuito, a pesquisa doutoral de Ilana Magalhães, que problematiza o campo da produção de estudos ambientais e relatórios de impacto ambiental, e a pesquisa de mestrado de Luan Arruda, que problematiza os impactos das políticas desenvolvimentistas e a 'insegurança ontológica' provocadas aos sujeitos nessa região.

Numa análise mais ampliada, temos debatido como as políticas de energia e mineração têm se configurado como o eixo integrador de como operam as instituições e o poder modernos, destrinchando as situações identitárias, ambientais e econômicas dessa região através de uma lente antropológica. Os desdobramentos de tal podem ser visualizados em dois importantes materiais produzidos nesse campo, o primeiro, um Mapa Síntese sobre as ações coletivas de povos tradicionais e os conflitos socioambientais presentes no Sertão de Itaparica, e o segundo, um Boletim Informativo sobre o projeto de construção da Central Nuclear do Nordeste em Itacuruba. A elaboração de tais materiais possibilitou boa parte das experiências etnográficas que embasaram as ideias presentes neste texto.

O Boletim Informativo, intitulado pelos povos tradicionais de Itacuruba: 'Resistimos para existir: dizemos não à usina nuclear no Rio São 
Francisco!', aponta reflexões às questões que até agora empreendemos em três direções: uma referente à existência de populações, sobretudo étnicas, na região de confluência dos projetos de desenvolvimento; outra sobre as resistências empreendidas por estes no intuito de assegurarem as suas existências coletivas; e, por último, a renúncia de um novo megaprojeto energético no Rio São Francisco.

As existências dos povos tradicionais em Itacuruba possibilitam a compreensão de uma ampla rede que compõe a diversidade de relações socioculturais que afirmam as continuidades históricas dessas populações nessa região. Estamos aqui! Sempre estivemos! São afirmações que evidenciam que os processos de 'existências' estão imbricados em formas de resistir para que tais existências sejam garantidas. O despontar de um repertório confrontacional antinuclear nessa região, estabelecido, sobretudo, pelas populações tradicionais, propõe a revitalização das formas de resistências a uma 'velha' história do caminho do desenvolvimento pelo Rio São Francisco, que já se apresenta como uma locomotiva desenfreada a ponto de atropelar as significações, histórias, existências, interesses e direitos dos grupos diretamente impactados.

\section{Notas:}

1 O presente trabalho foi apresentado e premiado com menção honrosa no VII Encontro de Desenvolvimento e Meio Ambiente, realizado em 13 de junho e 12 de julho de 2019, na Universidade Federal de Pernambuco.

2 Frente às distintas categorizações político-administrativas que existem para a região do semiárido pernambucano, optamos por nesse trabalho considerar a classificação de Região de Desenvolvimento (RD) do Estado, conforme legislação governamental, Lei $\mathrm{n}^{\circ}$ 13.306, de 01 de outubro de 2007, que agrupa sete municípios: Belém do São Francisco, Carnaubeira da Penha, Floresta, Itacuruba, Jatobá, Petrolândia e Tacaratu. A classificação de RD do Estado possibilita-nos compreender que essa divisão regional está articulada a uma estratégia de aplicação de investimentos de iniciativa privada, consorciados pelo Estado, estando entre esses o projeto da Central Nuclear do Nordeste. 
3 As atividades do núcleo Pernambuco do Projeto Nova Cartografia Social resultaram em três fascículos: 1 . Com a comunidade quilombola de Conceição das Crioulas, Salgueiro - PE em 2006; 2. Com o Povo indígena Xukuru do Ororubá, Pesqueira - PE em 2012; 3. Com as associações e times de futebol do bairro de Santo Amaro em Recife, em 2014. Referente às atividades na Região de Itaparica, foi elaborado um Boletim Informativo sobre a questão nuclear em Itacuruba e um Mapa Síntese das ações coletivas e conflitos socioambientais nesta região. Todos os materiais produzidos estão disponíveis no site do Projeto Nova Cartografia Social (PNCS).

4 A "tradição inventada" para Almeida (2017:14) refere-se ao que Hobsbawm afirma em que certamente as tradições são verdadeiras, embora inventadas, já que expressam uma identidade política construída em determinada situação histórica.

5 Notícias intituladas: 'Sertanejos sofrem com depressão' de 25 de maio de 2007. Disponível em: http://www.cremepe.org.br/2007/05/25/sertanejos-sofrem-comdepressao/; acesso em 27/11/018; 'Itacuruba afogada na tristeza' de 27 de maio de 2007. Disponível em: http://www.cremepe.org.br/2007/05/27/itacuruba -afogada-na-tristeza/; acesso em 27/11/018; 'Dependência química preocupa em Itacuruba' de 25 de agosto de 2011. Disponível em: http://www.cremepe.orNg. br/2011/08/25/dependendencia-quimica-preocupa-em-itacuruba/; acesso em 27/11/018.

6 O valor do investimento está baseado no levantamento realizado pela Neoway empresa de big data analytics que monitora fontes públicas e mercadológicas - noticiado no Jornal do Comércio, em 12 de agosto de 2018. Disponível em: https://jconline.ne10.uol.com.br/canal/economia/pernambuco/noticia/2018/08/12/pernambuco-tem-mais-de-15-mil-obras-paralisadas-350547.php; acesso em 21/07/2019.

7 Notícia intitulada: 'Itacuruba: a terra dos deprimidos' de 20 de agosto de 2011. Disponível em: https://jconline.ne10.uol.com.br/canal/cidades/geral/ noticia/2011/08/20/itacuruba-a-terra-dos-deprimidos13523.php; acesso em $16 / 05 / 2019]$.

8 Notícia intitulada: 'Eletronuclear escolhe cidade de Itacuruba como opção para sediar usina atômica do Nordeste', publicada em 18 fev. de 2011. Disponível em: https://blogs.ne10.uol.com.br/jamildo/2011/02/18/eletronuclear-escolhecidade-de-itacuruba-como-opcao-para-sediar-usina-atomica-do-nordeste/; acesso em 28/04/2019.

9 A Eletronuclear é uma empresa Subsidiária da Eletrobras (Responsável estatal pela geração e transmissão de energia elétrica no país), é uma empresa de economia mista e responde pela geração de aproximadamente 3\% da energia elétrica consumida no Brasil.

10 Notícia no site do Ministério de Minas e Energia intitulada: 'Eletronuclear inaugura escritório em Recife'. Disponível em: http://www.mme.gov.br/web/ guest/pagina-inicial/outras-noticas/-/asset_publisher/32hLrOzMKwWb/content/ eletronuclear-inaugura-escritorio-no-recife; jsessionid=9EFEB2F5A0CBD5C0B2C061ACCA591E17.srv155; acesso em 28/04/2019. 
11 Notícia intitulada: 'Projeto prevê nova central nuclear em Pernambuco', publicada em 21 de agosto de 2013. Disponível em: http://www.aben.com.br/noticias/projeto-preve-nova-central-nuclear-em-pernambuco\#noticia. 2013; acesso em 25/01/2019.

12 Esse documento trata- se de um material, em formato de slides, da apresentação do projeto de construção de um complexo de seis usinas nucleares no sítio designado como 'Belém de São Francisco'. Um fato curioso é que o material, disponível digitalmente no site da Eletrobrás / Eletronuclear, foi retirado do site em julho de 2018, mesmo mês que se publicara na Folha de São Paulo que o governo federal retomava a discussão do PNB e previa a construção de novas usinas nucleares no Brasil. O acesso ao material dava-se a partir deste link: http://www.eletronuclear. gov.br/LinkClick.aspx?fileticket=V-YqhiUeb10\%3D\&tabid=347.

13 As obras dessa central nuclear começaram em 2009, entretanto tal empreendimento só veio a funcionar em 2018.

14 Notícia intitulada: 'Temer retoma plano nuclear e governo prevê várias usinas', publicada em 15 de julho de 2018. Disponível em: https://folha.com/k7jt13d8; acesso em 28/04/2019.

15 Notícia intitulada: 'Brasil quer permitir estrangeiros na mineração de urânio, diz ministro', publicada em 15 de março de 2019. Disponível em: https://folha. com/sfxt9ip1; acesso em 28/04/2019.

16 Notícia intitulada: 'Ministro diz que governo planeja liberar mineração em terras indígenas', publicada em 04 de março de 2019. Disponível em: https://www. valor.com.br/empresas/6145777/ministro-diz-que-governo-planeja-liberar-mineracao-em-terras-indigenas; acesso em 28/04/2019.

17 Nota de esclarecimento sobre Angra 3, publicada pelo Ministério de Minas e Energia em 22 de janeiro de 2019. Disponível em: http://www.mme.gov.br/web/ guest/pagina-inicial/outras-noticas/-/asset_publisher/32hLrOzMKwWb/content/ nota-de-esclarecimento-sobre-angra-3; acesso em 28/04/2019.

18 Informações disponíveis no site da Eletronuclear, em:http://www.eletronuclear.gov.br/Paginas/default.aspx; acesso em 26/07/2019.

19 Em referência à Prado (1996), “A beleza traída. Percepção da usina nuclear pela população de Angra dos Reis”, trabalho apresentado na XX Reunião Brasileira de Antropologia, Salvador; e G. Silva (1999) Angra I e a Melancolia de Uma Era. Um Estudo sobre a Construção Social do Risco. Niteroi: Editora da UFF.

20 Notícia falsa.

21 Todos os depoimentos aqui citados foram realizados na oficina de cartografia social com os povos tradicionais de Itacuruba, organizada pela secção Pernambuco do PNCS e realizada em maio de 2018 no município de Floresta, Sertão de Itaparica, PE.

22 Notícia intitulada: 'Dom Limacêdo leva apoio a causa de Itacuruba', publicada em 15 de agosto de 2019. Disponível em: https://www.arquidioceseolindarecife. org/dom-limacedo-leva-apoio-a-causa-de-itacuruba/; acesso em 30/08/2019. 


\title{
Referências:
}

ALMEIDA, Alfredo W. 2017. "Repensando a acão antropológica: prefácio à edição de 2016”. In ALMEIDA, A. \& MOURÃO, L. (eds.): Questões agrárias no Maranhão contemporâneo, pp. 29-61. Manaus: UEA Edições.

2004. "Terras tradicionalmente ocupadas: processos de territorialização e movimentos sociais". Revista Brasileira de Estudos Urbanos e Regionais, 6(1):9-32.

ALONSO, A. \& BOTELHO, A. 2012. "Repertórios de ação coletiva e confrontos políticos: entrevista com Sidney Tarrow". Sociologia e Antropologia, 2(3):11-19.

BROOKS, Andrew. 2012. "Radiating Knowledge: the public anthropology of nuclear energy". American Anthropology, 114(1):137-145.

LEITE LOPES, José S. (Ed.). 2004. A ambientalização dos conflitos sociais. Rio de Janeiro: Relume Dumará.

MCADAM, D., TARROW, S. \& TILLY, C. 2009. "Para mapear o confronto político". Lua Nova, 76:11-48.

NADER, L., CESARINO, L. \& HEBDON, C. 2010. The Energy Reader. Chichester: Wiley-Blackwell.

PINGUELLI ROSA, Luiz. 1988. "Características da estrutura de produção da energia nuclear no Brasil”. In PINGUELLI ROSA, L., SIGAUD, L. \& MIELNIK, O. (eds.): Impactos de grandes projetos hidrelétricos e nucleares: aspectos econômicos, tecnológicos, ambientais e sociais, pp.39-69. São Paulo: COPPE/ Marco Zero/CNPq.

RIBEIRO, Gustavo L. 2008. "Poder, redes e ideologia no campo do desenvolvimento". Novos Estudos CEBRAP, 80:109-125.

SCOTT, James. 2002. "Formas cotidianas da resistência camponesa". Raizes, 21(1):10-31.

SCOTT, Russel P. 2009. Negociações e resistências persistentes: agricultores e a barragem de Itaparica num contexto de descaso planejado. Recife: Ed. Universitária da UFPE.

SILVA, Whodson. 2019. O conto das quatro mil almas: uma etnografia do confronto de Indigenas e Quilombolas com a Central Nuclear do Nordeste em Itacuruba. Dissertação de Mestrado. Recife: Universidade Federal de Pernambuco.

\begin{abstract}
The aim of the present study was to question the socio-political field related to the implementation of the Nuclear Power Plant of the Northeastern in Itacuruba County, Pernambuco State - Brazil. Our analysis takes into account the place of traditional peoples in the arena of socio-environmental conflicts. The current scenario points towards the consolidation of a nuclear policy that takes prioritizes factors such as the
\end{abstract}


military relevance of nuclear technologies and the sophistication embodied by the nuclear technology, which is seen as the power source of the future. Accordingly, traditional communities living in Itacuruba have made a list of confrontations to assure protection to their specific territorialities due to the implementation of the nuclear complex in São Francisco River. Such amendments establish a repertoire of collective actions and political confrontations in Sertão do Pernambuco region.

Keywords: Traditional people and communities, Northeastern Nuclear Plant, Antinuclear movement.

Recebido em abril 2020.

Aprovado em julho 2020. 